\title{
Fostering children's relationship with nature: exploring the potential of Forest School
}

\section{Authors:}

Dr Michelle A Smith. Independent researcher, Hull. Michelle.anne@hotmail.co.uk Michelle has studied biology and ecology to doctorate level and since gaining her $\mathrm{PhD}$ has worked on a number of projects with a focus on methods and outcomes of river rehabilitation, environmental impact assessment and the role of fisheries in sustainable food production. She is particularly interested in environmental sciences and conservation, interactions between society and nature and how people learn from and about the natural environment.

Ally Dunhill. School of Education and Social Sciences, University of Hull. a.dunhill@hull.ac.uk 01482462007

Ally has spent over 20 years working in a range of settings and organisations with children, young people and their families in the Netherlands, Germany, UK and the Gulf. Her teaching and research focus on the lived experiences of children and young people, human rights and rights education (including UNICEF UK's Rights Respecting Schools Award). She is particularly interested in involving children and young people in research to gather their accounts, and how they as individuals are making sense of their experiences of the world around them. Ally is currently the Associate Dean for Student Experience in the Faculty of Arts, Cultures and Education at the University of Hull; an Associate of the Wilberforce Institute in Hull, UK and a Non -Resident Fellow of TRENDS Research and Advisory in Abu Dhabi, UAE.

Professor Graham W Scott, School of Environmental Sciences, University of Hull. g.scott@hull.ac.uk 01482466424

Graham Scott is Professor of Bioscience Education at the University of Hull. He is an experienced ecological fieldworker and field course teacher. Graham's research interests are centred around fieldwork as pedagogy and the value of learning out of doors.

\section{Acknowledgements:}

Funding and grants awarded: The authors received no direct funding for this research. 


\title{
Fostering children's relationship with nature: exploring the potential of Forest School
}

\begin{abstract}
Forest School offers children opportunities to explore the natural environment regularly over an extended period of time. It is based on six key principles, one of which states Forest School fosters a relationship with nature and develops long term pro-environment attitudes through regular personal experiences in nature. We consider to what extent this aim is achieved by exploring the published evidence. We identify that a relationship with nature could be demonstrated under six themes although there is little robust evidence to support this. We suggest further research is carried out directly linked to this aim of Forest School.
\end{abstract}

Keywords: Outdoor education; relationship with nature; Forest School, learning outdoors

\section{Introduction}

The Forest School initiative was brought to the UK by the early years staff of Bridgewater College, Somerset following an exchange visit to Denmark in 1993. They established the first Forest School (Maynard, 2007a and b) and wider development of the movement in the UK which began in the mid 1990's (Murray and O’Brien, 2005; O’Brien and Murray, 2006) has continue to spread throughout England, Scotland, Wales and Northern Ireland (Cree and McCree, 2012). Forest School has the same underlying principles and is closely related to the Danish early years Udeskole model (Massey, 2005; Maynard, 2007a) based on the Scandinavian idea that contact with nature is extremely important for children (Murray and O’Brien, 2005; O’Brien and Murray, 2006). It is acknowledged amongst outdoor learning practitioners that Forest School is something which builds upon the UK's outdoor learning heritage which itself dates back to at least the nineteenth century (www.forestschoolassociation.org). The philosophy of Forest School is to encourage positive outdoor experiences through natural play to people of any age group (Horseman, 2010) (although our focus here, and the focus in the UK more generally is the early years to secondary age group). One of the stated aims of Forest School is that participation fosters a relationship with nature and develops long term pro-environment attitudes through regular personal experiences in nature (www. Forestschoolassociation.org). In this paper we consider the extent to which this aim is achieved through an exploration of the published evidence.

Forest school is unique in that the emphasis is on learning outside of the classroom with the freedom to explore the natural and changing environment (Massey, 2005). Forest School permits contact with the natural environment through regular activities in a woodland setting, the opportunity for creative, diverse and imaginative play and the opportunity for children to develop their own lived experiences whilst developing a responsible attitude to risk within strict safety routines and established boundaries (Murray and O’Brien, 2005; O’Brien and Murray, 2006). A key feature of Forest School is the importance of individual and directed learning with a child-led focus (Knight, 2009; Massey, 2005; Passy and Waite, 2011) means practitioners observe how the child engages with Forest School and their interests and adapts lessons to compliment this and enhance the learning process (Falch-Lovesay, Lord and Ambrose, 2005; O’Brien and Murray, 2007). What sets Forest School apart from other learning experiences is that attendance regularly over an extended period of time results in beneficial outcomes that are not available as a result of a few isolated or disjointed sessions (Murray and 
O’Brien, 2005; O’Brien and Murray, 2006; Borradaile, 2006). The Forest School ethos is based on six principles (that we interpret as aims) which were agreed by the UK Forest School community in 2011 (www. Forestschoolassociation.org), these may be summarised as:

1. Forest school takes place over an extended period of time allowing for frequent and regular sessions in a woodland or other natural environment; it is based upon observations, physical and behavioural boundaries and collaborative work between learners and practitioners.

2. Forest School aims to promote the holistic development of all participants; to develop physical, social, cognitive, linguistic, emotional, social and spiritual abilities of the learner and where appropriate to link experiences to home, work and/or school education.

3. Forest School offers learners the opportunity to take supported risks appropriate to themselves and the environment.

4. Forest School is delivered by qualified practitioners who continuously maintain and update their practice and there is a high ratio of adults/practitioners to learners.

5. Forest School uses a range of learner centred processes to create a community for learning and development that integrates play and choice and is responsive to the needs and interests of the learners.

6. Forest School takes place in a woodland or natural setting and aims to foster a relationship with nature and the development of long term pro-environment attitudes through regular personal experiences in nature.

Numerous evaluations, reviews and studies of Forest School have been undertaken (Lovell, O'Brien and Owen, 2010) and from these a number of positive outcomes have been reported. These include increased self-confidence and self-esteem, enhanced social skills, improved language and communication, increased motivation to learn, the development of physical skills, increased knowledge and understanding of nature and the outdoors (Murray et al., 2003; Murray and O’Brien, 2005; Davis and Waite, 2005; Massey, 2005; Falch-Lovesay, Lord and Ambrose, 2005; O’Brien and Murray, 2006; O’Brien and Murray, 2007; O’Brien, 2009; Attwood, 2010; Horseman, 2010; Lovell, O’Brien and Owen, 2010; Berrington, 2012; Ridgers, Knowles and Sayers, 2012; Slade, Lowery and Bland, 2013). Other studies report increased physical activity during the Forest School day in comparison to a regular school day as a further benefit of Forest School (Lovell, 2009; Lovell, O’Brien and Owen, 2010; Austin, Knowles and Sayers, 2013). Forest School can also shift the perspectives of teachers and children through participation in novel pupil-teacher interactions outside of the formal classroom setting which foster a reciprocal relationship through a shared approach to common challenges in the outdoor environment (Murray and O’Brien, 2005; O’Brien and Murray, 2006; O’Brien, 2009; Berrington, 2012; Slade, Lowery and Bland, 2013). Forest School also provides a means by which children, and particularly those children for whom such opportunities play in the natural environment are being lost (O’Brien and Murray, 2007), can gain regular access to the natural environment (Slade, Lowery and Bland, 2013). Given that children are thought to be spending less time playing in the natural environment, providing access to the environment through the education system is one way to increase children's contact with nature and offer children the opportunity to learn about and engage with it (Harris, 2015). This may be beneficial to both the child and nature as evidence suggests sensitivity towards the environment appears to be rooted in childhood experiences in nature leading to bonds with and positive values towards the natural environment (Chawla and Flanders Cushing, 2007; Hinds and Sparks, 2008; Ernst and Theimer, 2011). Increasing the amount of time spent outdoors within nature can also enhance a child's relationship with nature and enhance learning by enabling knowledge and skill acquisition, and emotional development (Waite et al., 2016). Encouraging an affinity with 
nature within children is also vital in inspiring them to protect it for future generations (Bragg et al., 2013). Forest School Principle (aim) six, to 'foster a relationship with nature and develop long term pro-environment attitudes through regular personal experiences in nature' is the focus of our discussion. Here we explore the published evidence to determine the extent to which this aim is achieved.

\section{Does Forest School foster a relationship with nature and the development of long term pro-environment attitudes?}

To explore the evidence that Forest School fosters a relationship with nature and the development of long term pro-environment attitudes we searched for published Forest School studies using a conventional internet search engine. From these, we selected those studies which made a reference to nature (Table one) as the basis for our analysis. From an interpretive analysis of the papers through repeated reading, the authors independently identified key themes that they believed had the potential to demonstrate a positive relationship with nature. Then through reflective discussion, the six key themes outlined in Table 2 were developed.

[Table 1 near here]

[Table 2 near here]

\section{Increased knowledge about nature/environment}

Children demonstrating increased knowledge about nature and the environment was one of the most frequently reported outcomes of Forest School in the literature we explored and Knight (2009) suggested it is the most obvious outcome of Forest School. Through Forest School children showed increased instances of observing and noticing things around them (Murray et al., 2003), were able to gain knowledge about the natural phenomena around them (Murray and O'Brien, 2005) and were able to recognise and learn the names of trees and animals, especially insects (Murray and O’Brien, 2005; Ridgers, Knowles and Sayers 2012; Slade, Lowery and Bland, 2013; Harris, 2015) which in some cases lead to the children developing a level of classification (Massey, 2005; Harris, 2015). In some cases, parents also reported that their child had learnt about animals and trees and was able to name trees and animals (Knight, 2009; Slade, Lowery, Bland, 2013). However, Slade, Lowery and Bland (2013) also reported that the development of knowledge, understanding, interest and respect for the natural environment were not specifically mentioned by teachers.

\section{Understanding of the outdoor environment/nature}

Evidence suggesting an understanding of the natural environment was reported less frequently than evidence suggesting increased knowledge. Through Forest School children were able to gain an understanding of their natural surroundings through exploration and carrying out their own investigations. For example by floating leaves and sticks down a stream to see which would float furthest and speculating where they would go (Davis and Waite, 2005). Or through conversations which developed from the children's activities. For example splashing in a puddle on a rainy day led to conversations about where the puddle came from and where it goes (Massey, 2005). Falch-Lovesay, Lord and Ambrose (2005) suggest that through being outdoors and observing nature first-hand children began to understand ecological concepts. In addition Murray et al. (2003) suggested that through Forest School children gained an understanding of the consequences of their actions for example not dropping litter. Ridgers, Knowles and Sayers (2012) also reported that through Forest School children gained an appreciation of the natural environment including a respect for the habitat of other living creatures, they noted that three children were able to explain why red squirrels in neighbouring woodland were dying and could justify their points based on their own experiences. 


\section{Improved relationship with the outdoors}

An improved relationship with the outdoors was one of the outcomes of Forest School most frequently mentioned in the studies we explored. Harris (2015) noted the development of a relationship with nature was one of the most commonly mentioned themes (described as recognising and using natural things; caring for the natural world; developing a sense of place) occurring in their interviews with Forest School practitioners. This was echoed in a number of other studies whose findings suggest that through Forest School children are more interested in and motivated to learn about, their natural surroundings and curious to find out more about the world around them, commenting on and wanting to be close to wildlife (Murray and O’Brien, 2005; Attwood, 2010; Ridgers, Knowles and Sayers, 2012).

Murray et al. (2003) stated that Forest School resulted in children being visibly 'at home' in the outdoors, happy to roam and explore on their own and demonstrating ownership of, a relationship with, and pride in a place. Indeed, Davis and Waite (2005) noted that Forest School resulted in children developing a sense of place and being able to express beliefs such as where a stream might flow to, and after Forest School children were able to identify key points on a map of the site with which they had become familiar. Massey (2005) also observed that children showed confidence and independence in the outdoor environment and that parents expressed wonderment at their child's level of confidence. Murray et al. (2003) suggest Forest School leads to an improved relationship with the outdoors through processes such as games, being outdoors in all weathers and seasons and children taking responsibility for their own risk assessments. Processes that result in specific outputs such as routines in Forest School that are similar to routines in class, collection of bugs and insects for classroom nature projects, exploration of the woodland area, dressing in suitable clothing, following and understanding safety rules and a realistic understanding of potential risks are also thought to be particularly valuable (Murray et al. (2003). This in turn leads to the desired outcomes of linking outdoor routines to indoor routines, demystifying the environment and bringing the outdoors indoors, having the freedom to explore wilderness in a safe way, encouraging more independent exploration and building confidence and realising it is alright to get wet and dirty (Murray et al., 2003).

\section{Pride in knowledge of nature/local environment}

In Murray et al.'s (2003) report Forest School practitioners and other education professionals note that they anticipate that children will develop pride in a place following Forest School and Murray and O'Brien (2005) report that children show pride in their knowledge and familiarity with the setting of a Forest School. These children express a positive desire to take their parents to the Forest School site, or to similar woodland setting to display the knowledge and skills that they have gained.

\section{Ownership of the local environment}

Murray et al.'s (2003) report also indicates that Forest School practitioners and other education professionals anticipate that children will develop ownership of a place following Forest School. This is reflected by Falch-Lovesay, Lord and Ambrose (2005), Berrington (2012) and Harris (2015) who noted that children develop an attachment to the site. As an example, Knight (2009) reported that children were angry at changes to "their" camp. Murray et al. (2003) propose Forest School results in these outcomes through processes such as planting, looking after a piece of woodland over time, undertaking nature projects, showing visitors around and involving them in Forest School. These activities results in specific outputs such as making things in the wood e.g. shelters and involving parents and carers in activities leading in turn to 
the desired outcomes by actively taking care of outdoor space, becoming observant of changes when returning to the same plot over time, encouraging the recognition of sights and sounds of flora and fauna, talking positively about Forest School and sharing experiences out of school.

\section{Impact beyond Forest School}

Evidence in the reports we explored suggests Forest School has the potential to have impacts beyond those of immediate participation. Murray and O’Brien (2005) report that Forest School practitioners and other education practitioners anticipate Forest School will have a ripple effect. The impact beyond Forest School is demonstrated in a number of ways in the reports we explored including external practitioners demonstrating a different attitude towards participants and towards Forest School, children wanting to take their parents to Forest School or to a woodland setting and parents having an opportunity to gain a different view of the outdoors for example a different view of the perceived risks (Murray and O'Brien, 2005; Berrington, 2012). Children also reported hunting for minibeasts in their own gardens and how they handled them once they had found them (Ridgers, Knowles and Sayers, 2012). There was, however, no indication of the actual longevity of these impacts in the studies reviewed. Turtle, Convery, I. and Convery, K. (2015) found that there was a statistically significant difference in pro-environmental attitude, which they define as 'ecological awareness and concern for the natural world and its components, leading to involvement in, and knowledge of, activities that have a positive impact on the environment for extrinsic reasons', between children who had participated in Forest School and those who had not. They found that children who had participated in Forest School demonstrated a more pro-environmental attitude.

\section{Discussion}

Although we found examples of practice and outcomes that might align with aim six, our exploration of published Forest School studies revealed no studies which focussed specifically on Forest School's potential to foster a relationship with nature and only one study (Turtle, Covery, I. and Convery, K., 2015) which investigated the development of pro-environment attitudes following participation in Forest School.

It is thought that repeated direct experiences of nature enable an individual to form a relationship with nature, and ultimately motivate individuals to protect it (Brügger, Kaiser and Roczen, 2010; Beery and Wolf-Watz, 2014). Regular participation in Forest School may, therefore, have the potential to foster within children a relationship with nature. The studies we explored did not specifically assess the extent to which children develop a relationship with nature during and after participation in Forest School. However, through our exploration we have identified six themes that we believe demonstrate at least the potential for Forest School to foster a relationship between children and nature. These themes suggest that through Forest School children become more aware of, interested in and want to learn more about the natural environment, there are increased instances of children noticing things around them, and some children develop the knowledge to name animals and trees and begin to understand ecological concepts. Through participation in Forest School, children may become more comfortable in the outdoors and want to spend more time in the natural environment. Participants are proud of the knowledge they have developed and wanted to share their knowledge with others. We suggest that a greater awareness of and a desire to spend more time in the natural world indicates the potential for an improved relationship with the natural environment. It also became clear through our exploration of the published literature that authors and practitioners believe that participation in Forest School has the potential to foster a relationship between children and nature although there is currently no robust assessment of this relationship. 
The development of a relationship with nature, cognitive and/or emotional, can be described using the environmental connectedness perspective which suggests that through spending time in nature an individual will feel more connected to nature, care more about nature and ultimately be inspired to protect nature (Beery and Wolf-Watz, 2014). Children's connection to nature is important to both the child and the natural environment (Richardson et al., 2016) and the importance of children's connection to and respect for nature is recognised in the UN Convention on the Rights of the Child which are a set of international legal obligations ratified in December 1991 in the UK (UNICEFUK, n.d.) and the World Congress of the International Union for the Conservation of Nature (IUCN) in 2012 adopted a motion endorsing the "Child's Right to Connect with Nature and to a healthy environment” (World Conservation Congress, 2012). Research by Richardson (2015) suggested a child's connection to nature is associated with more time spent in nature and connection to nature is best started in childhood through regular contact with nature. There has been recent recognition of the benefits of outdoor learning with physical, social, personal and curricular benefits being reported in response to connection with the environment (Edwards-Jones, Waite and Passy, 2016). Increased contact with nature has also been said to improve the way children learn allowing them to learn differently through cognitive impacts (greater knowledge and understanding), affective impacts (attitudes, values, beliefs and self-perceptions), interpersonal and social impacts (communication skills, leadership and teamwork), and physical and behavioural impacts (fitness, personal behaviours and social actions) (Dillon et al., 2005 in Moss, 2012) in addition children engaged in learning outside the classroom achieve higher test scores (Malone 2009; Scott and Boyd, 2014), have increased confidence and self-esteem, show leadership qualities, are socially competent, have greater physical fitness and motor skill development and are more environmentally aware (Malone 2009). Richardson (2015) also suggests that a connection to nature is important to learning many core academic subjects and children who are more connected to nature have significantly higher attainment in English as well as having significantly higher health, life satisfaction, pro-nature behaviours and pro-environmental behaviours.

We were also interested in whether there was evidence to suggest the second part of aim six, Forest School develops long-term pro-environment attitudes, was met. Previous research suggests connectedness to nature encourages pro-environmental behaviour (Geng et al., 2015) thus suggesting if Forest School does foster within children a relationship with nature this may lead to the development of pro-environment behaviours. It was noted by Murray et al. (2003) that children become more aware of the consequences of their actions, for example dropping litter. Whilst this does not directly indicate that children develop more pro-environment behaviours it does suggest that children may become more aware of the fact that their actions can have an impact upon the natural environment. The only study investigating the impact of Forest School on pro-environment behaviours (Turtle, Convery, I. and Convery, K., 2015) suggested that participation in Forest School could have a positive impact on pro-environment behaviours as children who had participated in Forest School scored more highly on questionnaires assessing pro-environment attitudes than those who had not participated in Forest School. However, this study was limited in the number of participating schools (three participating in Forest School and three not participating in Forest School) and gave no indication of the long term effects of participation in Forest School on pro-environment attitudes and behaviours.

The studies we explored had a wide range of research foci and used a wide range of data collection methods to capture the outcomes of Forest School (Table one). However, the majority of them place attention on the social and developmental benefits of Forest School. 
Whilst this gives a broad view of the outcomes of Forest School it makes it difficult to replicate methods and compare results between studies to draw robust and wide-reaching conclusions about the outcomes of Forest School. Whilst there is a wealth of Forest School research available it is currently fragmented. The evidence we found and reported here was extracted from studies reporting a wide range of outcomes of Forest School. Many of the studies we explored either used methods building upon those used by Murray and O’Brien (2005) or compared their findings to the eight themes suggested by Murray and O'Brien (2005) (1. Confidence, 2. Social skills, 3. Language and Communication, 4. Motivation and concentration, 5. Physical skills, 6. Knowledge and understanding, 7. New perspectives, 8. Ripple effects beyond Forest School). However, none of the studies specifically addressed the success of Forest School in achieving aim six, to foster a relationship with nature and only a limited number refer to the development of a relationship with nature. Furthermore only one study (that of Turtle, Covery, I. and Convery, K., 2015) specifically addressed the possibility that participation in Forest School leads to the development of long-term pro-environment attitudes, but this study is limited by duration and sample size.

The majority of the evidence recorded in the studies we explored is based upon observations of Forest School participants by practitioners and education professionals or is the voice of practitioners captured through interviews. The principles (which we interpret as aims) of Forest School have been established by the Forest School community (www. Forestschoolassociation.org) and the propositions for change developed by Murray and O'Brien (2005, 2006), often used in later studies, were also developed by practitioners and wider stakeholders based upon how they felt Forest School had an impact on children (Murray and O'Brien, 2005). It, therefore, seems likely that evaluations corroborate predicted benefits, but this is done without robust measurement methodologies (see also Waite, Bølling and Bentsen, 2015). Much of the evidence available to support claims Forest School meets its aims is anecdotal and observational, which is notoriously difficult to capture (O'Brien and Murray, 2007). We note that Murray et al. (2003) and Murray and O’Brien (2005) state that it requires more than quantitative research to assess the outcomes of Forest School but we suggest there is a need for a robust measurement of whether Forest School fosters a relationship with nature and thus achieves aim six. The timescale and regularity children participate in Forest School also vary between studies meaning there is no indication of the optimum timescale over which participation in Forest School needs to occur for its aims to be met. Since a relationship with nature, and its potential benefits, is thought to develop over regular, recurring experiences in nature it would be beneficial to know what timescale children need to participate in Forest School for such a relationship to develop.

\section{Conclusions and implications}

Given the potential benefits of fostering children's relationships with nature, we suggest greater attention should be paid to whether children's participation in Forest School results in aim six 'to foster a relationship with nature and develop long term pro-environment attitudes through regular personal experiences in nature' being met. We suggest that a priority should be the development of a systematic methodology for measuring a child's relationship with nature before, during and after Forest School to identify whether Forest School fosters a relationship with nature and over what timescale and frequency children need to participate in Forest School for a relationship with nature to develop. We also suggest there is a need to measure children's relationship with nature post participation in Forest School to identify whether Forest School has a long term impact on children's relationship with nature and whether this results in proenvironment attitudes and behaviours which persist after participation in Forest School has ceased. 



\section{References}

Attwood, J. 2010. Exploring the Benefits of a Forest School Project in Twerton, Bath. (http://forestofavontrust.org/wp-content/uploads/2011/10/Forest-School-final-reportFeb2011.pdf).

Austin, C., Knowles, Z. and Sayers, J. 2013. Investigating the effectiveness of Forest School sessions on children's physical activity levels. The Mersey Forest in partnership with the Physical Activity Exchange at Liverpool John Moores University (http://www.merseyforest.org.uk/files/documents/1341/Austin,+C.,+Knowles,+Z.+and+Sayer $\mathrm{s},+\mathrm{J} .+$ Forest+School+Evaluation.pdf).

Beery, T.H. and Wolf-Watz, D. 2014. Nature to place: Rethinking the environmental connectedness perspective. Journal of Environmental Psychology 40 pp. 198-205. DOI:10.1016/j.jenvp.2014.06.006

Berrington, A. 2012. The Impact of Forest Schools in Bradford. BCEP. (http://bradfordforestschools.co.uk/wp-content/uploads/2012/03/BCEP-Forest-SchoolImpact-Assessment-Report.pdf).

Borradaile, L. 2006. Forest School Scotland An Evaluation final report. Report to Forestry Commission Scotland and Forest Education Initiative Scotland.

Bragg, R., Wood, C., Barton, J. and Pretty, J. 2013. Measuring connection to nature in children 8-12: A robust methodology for the RSPB (https://www.rspb.org.uk/Images/methodologyreport tcm9-354606.pdf).

Brügger, A., Kaiser, F.G. and Roczen, N. 2011. One for All? Connectedness to Nature, Inclusion of Nature, Environmental Identity, and Implicit Association with Nature. European Psychologist 16 (4) pp. 324-333. DOI: 10.1027/1016-9040/a000032.

Cree, J. and McCree, M. (2013) A Brief History of Forest School in the UK - Part 2. Horizons, 62 pp. 32-35 (www.outdoor-learning.org).

Chawla, L. and Flanders Cushing, D. 2007. Education for strategic environmental behaviour. Environmental Education Research, 13:4, 437-452, DOI: 10.1080/13504620701581539

Davis, B. and Waite, S. 2005. Forest Schools: an evaluation of the opportunities and challenges in Early Years Final Report January 2005. University of Plymouth (https://www.plymouth.ac.uk/uploads/production/document/path/6/6761/Forestschoofinalrep ort2.pdf).

Dillon, J., Morris, M., O’Donnell, Reid, A., Rickinson, M. and Scott, W. 2005. Engaging and Learning with the Outdoors - The Final Report of the Outdoor Classroom in a Rural Context Action Research Project. Final Report (http://www.bath.ac.uk/cree/resources/OCR.pdf).

Edwards-Jones, A., Waite, S. and Passy, R. 2016. Falling into LINE: school strategies for overcoming challenges associated with learning in natural environments. Education 3-13 DOI: 10.1080/03004279.2016.1176066. 
Ernst, J. and Theimer, S. 2011. Evaluating the effects of environmental education programming on connectedness to nature Environmental Education Research 17 (5) pp. 577-598 DOI: 10.1080/13504622.2011.565119.

Falch-Lovesay, S., Lord, C., and Ambrose, L. 2005. Forest School in Norfolk - Pilot Study Report and Evaluation. Norfolk County Council (http://www.schools.norfolk.gov.uk/view/ncc104249).

Geng, L., Xu, J., Zhou, W. and Zhou, K. 2015. Connections with Nature and Environmental Behaviours. Plos One 10 (5) DOI: 10.1371/journal.pone.0127247.

Harris, F. 2015. The nature of learning at forest school: practitioners' perspectives. Education 3-13, DOI: 10.1080/03004279.2015.1078833.

Hinds, J. and Sparks, P. 2008. Engaging with the natural environment: The role of affective connection and identity. Journal of Environmental Psychology 28 pp. 109-120. DOI:10.1016/j.jenvp.2007.11.001.

Horseman, L. 2010. Forest Schools Bradford West Reflections and Evaluation on Forest School Projects 2010. Bradford Community Environment Project (http://www.bradfordforestschools.co.uk/siteFiles/ReflectionsAndEvaluation.pdf).

Knight, S. 2009. Forest Schools and Outdoor Learning in the Early Years. Sage Publications.

Lovell, R. 2009. Physical activity at Forest School. Forestry Commission Scotland (http://owlscotland.org/images/uploads/resources/files/Physical_Activity_at_Forest_School_ Research.pdf).

Lovell, R., O’Brien, L. and Owen, R. 2010. Review of the research evidence in relation to the role of trees in formal education and learning (http://www.forestry.gov.uk/pdf/Education_and_learning_research_review_2010.pdf/\$FILE/ Education_and_learning_research_review_2010.pdf).

Malone, K. 2009. Every experience matters. An evidence based research report on the role of learning outside the classroom for children's development from birth to eighteen years (http://www.face-online.org.uk/face-news/every-experience-matters).

Massey, S. 2005. The benefits of a forest school experience for children in their early years. Readership: primary, secondary Topic 33 pp. 27-35 (http://www.forestschoolleader.com/wpcontent/uploads/2016/03/Massey-benefits-of-forest-school-research.pdf).

Maynard T. 2007a. Forest Schools in Great Britain: an initial exploration. Contemporary issues in Early Childhood 8 (4) pp. 320-331. DOI:10.2304/ciec.2007.8.4.320.

Maynard, T. 2007b. Encounters with Forest School and Faucault: a risky business? Education 3-13, 35 (4) pp. 379-391, DOI: 10.1080/03004270701602640.

Moss, S. 2012. Natural Childhood. The National Trust (https://www.nationaltrust.org.uk/documents/read-our-natural-childhood-report.pdf). 
Murray, R., Walker, P., Stanziola, J., Higginson, S. and Murphy, M. 2003. Forest School Evaluation Project A study in Wales April to November, 2003 (http://www.forestry.gov.uk/pdf/ForestSchoolWalesReport.pdf/\$FILE/ForestSchoolWalesRe port.pdf).

Murray, R. and O’Brien, L. 2005. "Such enthusiasm - a joy to see” An evaluation of Forest School in (http://forestry.gov.uk/pdf/ForestSchoolEnglandReport.pdf/\$FILE/ForestSchoolEnglandRepo rt.pdf).

O’Brien, L. and Murray, R. 2006. A marvellous opportunity for children to learn A participatory evaluation of Forest School in England and Wales. (http://www.forestry.gov.uk/pdf/fr0112forestschoolsreport.pdf/\$FILE/fr0112forestschoolsrep ort.pdf).

O’Brien, L. and Murray, R. 2007. Forest School and its impacts on young children: Case studies in Britain. Urban Forestry and Urban Greening 6 pp. 249-265. DOI:10.1016/j.ufug.2007.03.006.

O’Brien, L. 2009. Learning outdoors: the Forest School approach. Education 3-13 37 (1) pp. 45-60, DOI: 10.1080/03004270802291798.

Passy, R. and Waite, S. 2011. School gardens and Forest Schools in Children Learning Outside the Classroom From Birth to Eleven edited by Waite, S. Sage Publications.

Richardson, M. 2015. The Impact of Children's Connection to Nature A Report for the Royal Society for the Protection of Birds (RSPB) (https://www.rspb.org.uk/Images/impact_of_children\%E2\%80\%99s_connection_to_nature_t cm9-414472.pdf).

Richardson, M., Cormack, A., McRobert, L. and Underhill, R. 2016. 30 days wild: Development and Evaluation of a Large-Scale Nature Engagement Campaign to Improve WellBeing Plos One DOI: 10.1371.

Ridgers, N.D., Knowles, Z.R. and Sayers, J. 2012. Encouraging play in the natural environment: a child focussed case study of Forest School. Children geographies 10 (1) pp. 49-65. DOI:10.1080/14733285.2011.638176.

Scott, G.W. and Boyd, M. 2014. Getting more from getting out: increasing achievement in literacy and science through ecological fieldwork Education 3-13: International Journal of Primary, Elementary and Early Years Education DOI: 10.1080/03004279.2014.996242.

Slade, M., Lowery, C. and Bland, K. 2013. Evaluating the impact of Forest Schools: a collaboration between a university and a primary school. Support for Learning 28 (2) pp. 6672. DOI:10.1111/1467-9604.12020/

Turtle, C., Convery, I., Convery, K. 2015. Forest Schools and environmental attitudes: A case study of children aged 8-11 years. Cogent Education 2. DOI:10.1080/2331186X.2015.1100103. 
UNICEFUK (n.d.) United Nations Convention on the Rights of the Child (UNCRC) http://www.unicef.org.uk/UNICEFs-Work/UN-Convention/

Waite, S., Bølling, M. and Bentsen, P. 2015. Comparing apples and pears?: a conceptual framework for understanding forms of outdoor learning through comparison of English Forest Schools and Danish udeskole. Environmental Education Research 22 (6) pp. 868-892 DOI: 10.1080/13504622.2015.1075193.

Waite, S., Passy, R., Gilchrist, M., Hunt, A and Blackwell, I. 2016. Natural Connections Demonstration Project, 2012-2016: Final Report. Natural England Commissioned Reports, Number 215 (http://publications.naturalengland.org.uk/publication/6636651036540928).

World Conservation Congress. 2012. Congress Document WCC-2012-9.6

http://2012congress.iucn.org/member_s_assembly/agenda_and_documents/ 


\begin{tabular}{|c|c|}
\hline Study & Data collection methods used in the study \\
\hline $\begin{array}{l}\text { Murray et al., } \\
2003\end{array}$ & $\begin{array}{l}\text { Supported self-evaluation for Forest School Leaders and other } \\
\text { education professionals (1.Storyboard 2.Data collection and } \\
\text { analysis 3.Reflection poster (review)) }\end{array}$ \\
\hline $\begin{array}{l}\text { Murray and } \\
\text { O’Brien, } 2005\end{array}$ & $\begin{array}{l}\text { Self-appraisal methodology for Forest School Leaders and other } \\
\text { education professionals, builds upon methodology developed by } \\
\text { Murray et al., } 2003 \text { (1.Storyboard 2.Data collection and analysis } \\
\text { 3.Reflection poster (review)) }\end{array}$ \\
\hline Massey, 2005 & $\begin{array}{l}\text { Participatory case study. Data was collected regularly by the } \\
\text { researcher in collaboration with the Forest School leader and } \\
\text { nursery staff over a period of nine months. } \\
\text { Informal unstructured interviews were conducted with } \\
\text { participants during weekly Forest School sessions } \\
\text { Video and photographic data collected and observations recorded } \\
\text { in an anecdotal log during and after the researchers visit } \\
\text { A questionnaire for parents including open and closed questions }\end{array}$ \\
\hline $\begin{array}{l}\text { Davis and Waite, } \\
2005\end{array}$ & $\begin{array}{l}\text { Participant observation in Forest School programmes } \\
\text { Videotaped and photographic records of sessions } \\
\text { Interviews with teachers and children } \\
\text { A range of elicitation techniques with children } \\
\text { Questionnaires to parents } \\
\text { Forest School leader's evaluations } \\
\text { Mapping of a site and children's use of it. }\end{array}$ \\
\hline $\begin{array}{l}\text { Falch-Lovesay, } \\
\text { Lord and } \\
\text { Ambrose, } 2005\end{array}$ & $\begin{array}{l}\text { Reflection on sessions and informal communication with parents } \\
\text { by Forest School leaders } \\
\text { Photographs, recording possible schemas and wow moments, } \\
\text { overview of } 12 \text { key areas of learning and individual pupil } \\
\text { observations by Forest School leaders and teachers } \\
\text { overview of Forest School by teachers } \\
\text { home evaluation by parents and children }\end{array}$ \\
\hline Maynard 2007a & $\begin{array}{l}\text { Primarily individual semi structured interviews with three Forest } \\
\text { School practitioners trained at Bridgewater College }\end{array}$ \\
\hline Knight, 2009 & $\begin{array}{l}\text { Repeated and extended previous methods developed by Murray } \\
\text { and O'Brien, } 2005 \\
\text { Further data collection was oral questionnaires with children and } \\
\text { written questionnaires for parents from each of the four year } \\
\text { groups who had previously participated in Forest School during } \\
\text { the Foundation stage and written questionnaires for parents at the } \\
\text { second school which had recently participated in Forest School }\end{array}$ \\
\hline Attwood, 2010 & $\begin{array}{l}\text { Practitioners recorded observations of activities and dialogue } \\
\text { among children to create a diary for the individual child and the } \\
\text { whole group. Photographs and some video clips were also used } \\
\text { to document children's activities and experience. All adults } \\
\text { involved had a short period of reflection at the end of each session }\end{array}$ \\
\hline Berrington, 2012 & $\begin{array}{l}\text { Interviews with eight Forest School practitioners asking for } \\
\text { evidence to support the eight propositions for change suggested } \\
\text { by Murray and O’Brien, } 2005 \text {. }\end{array}$ \\
\hline $\begin{array}{l}\text { Ridgers, Knowles } \\
\text { and Sayers, } 2012\end{array}$ & $\begin{array}{l}\text { Baseline and post-programme small focus group discussions with } \\
\text { children to discuss their experiences of play and natural play } \\
\text { using a semi-structured format and open-ended questions. }\end{array}$ \\
\hline
\end{tabular}




\begin{tabular}{|l|l|}
\hline & $\begin{array}{l}\text { Following Forest School children were also asked what they } \\
\text { enjoyed, what they learnt and whether they continued to engage } \\
\text { in the activities they undertook at Forest School }\end{array}$ \\
\hline $\begin{array}{l}\text { Slade, Lowery } \\
\text { and Bland, 2013 }\end{array}$ & $\begin{array}{l}\text { Semi-structured interviews with one teacher, two teaching } \\
\text { assistants, the family and pastoral support officer, two volunteers, } \\
\text { the headteacher of the school, ten pupils and seven parents/carers. } \\
\text { Interview responses were analysed and compared to Murray and } \\
\text { O'Brien's (2005) findings }\end{array}$ \\
\hline Harris et al., 2015 & Semi-structured interviews with twenty Forest School leaders \\
\hline $\begin{array}{l}\text { Turtle, Convery, and Convery, } \\
\text { K., 2015 }\end{array}$ & $\begin{array}{l}\text { Questionnaires to assess environmental attitudes of children } \\
\text { aged eight to eleven years old administered to children who had } \\
\text { participated in Forest School (59 completed and returned) and } \\
\text { children who had not participated in Forest School (136 } \\
\text { completed and returned). A naturalistic inquiry-based study day } \\
\text { with one school as part of an exploratory Forest School session. }\end{array}$ \\
\hline
\end{tabular}

Table 1. The publications that have been examined in the current study and the data collection methods employed in each of them. 


\begin{tabular}{|l|l|}
\hline Theme & Studies \\
\hline Increased knowledge about & Murray and O’Brien, 2005 \\
nature/environment & Massey, 2005 \\
& Maynard, 2007a \\
& Knight, 2009 \\
& Ridgers, Knowles and Sayers, \\
& 2012 \\
& Berrington, 2012 \\
& Slade, Lowery and Bland, 2013 \\
& Harris,2015 \\
\hline Understanding of the outdoor & Murray et al., 2003 \\
environment/nature & Massey, 2005 \\
& Davies and Waite, 2005 \\
& Falch-Lovesay, Lord and \\
& Ambrose, 2005 \\
& Ridgers, Knowles and Sayers, \\
& 2012 \\
\hline Improved relationship with the outdoors & Murray et al., 2003 \\
& Murray and O’Brien, 2005 \\
& Massey, 2005 \\
& Davies and White, 2005 \\
& Attwood, 2010 \\
& Ridgers, Knowles and Sayers, \\
& 2012 \\
& Harris, 2015 \\
\hline Pride in knowledge of nature/local & Murray et al., 2003 \\
\hline Impact beyond Forest School & Falch-Lovesay, Lord and \\
& Ambrose, 2005 \\
& Knight, 2009 \\
& Berrington, 2012 \\
& Harris, 2015 \\
\hline Ownership of the local environment & Murray et al., 2003 \\
& Murray and O’Brien, 2005 \\
\hline & Ridgers, Knowles and Sayer, \\
& 2012 \\
& Berrington, 2012 \\
& Turtle, Convery, I. and Convery, \\
\hline
\end{tabular}

Table 2. The key themes assumed to indicate a relationship with nature emerging from our analysis of the published works that have been examined as part of the current study. 